\title{
Review Article: Remote Sensing, Surface Residue Cover and Tillage Practice
}

\author{
Obade Vincent de Paul
}

Department of Plant Science, South Dakota State University, Brookings, USA.

Email: vincent.obade@sdstate.edu

Received March 21 ${ }^{\text {st }}, 2011$; revised November $13^{\text {th }}, 2011$; accepted January $10^{\text {th }}, 2012$

\begin{abstract}
A growing world population and possible liquid fuel energy shortages are likely to result in worldwide agricultural intensification, and the possible expansion of non-sustainable practices. The adoption of non-sustainable practices could result in the loss of currently productive land, with potential impacts on human welfare and economic viability. One of the easiest techniques to maintain productivity is to maintain surface soil organic matter. However, developing reliable, cost effective and accurate methods for quantifying and monitoring crop residue cover (a major source of soil organic matter) that remains on top of the soil over large spatial extents constitutes a significant challenge. This article reviews potential remote sensing approaches for estimating surface residue cover with a view to mapping tillage practice.
\end{abstract}

Keywords: Remote Sensing; Residue Cover

\section{Introduction}

A majority of plant nutrients extracted from the soil are taken up by the crops, much of which ends up being consumed by industry or exported to other countries. The demand for crop residues for energy and feed production is likely to grow in future, contrary to the past, whereby crop residues were primarily returned to the soil $[1,2]$. Crop residues i.e. plant litter or non photosynthetic vegetation (NPV), can function as sources or sinks of carbon depending on the type of land management [3-5].

The retention of crop residue is important for minimizing soil degradation, and soil carbon depletion, both of which are intensified by soil mismanagement [6-9]. Modeling carbon dynamics remains the greatest source of uncertainty in climate scenarios [10]. As stated in [11], information on tillage practices can act as a baseline for developing a carbon trading system useful for regulating carbon emissions. Recently research has focused on the repercussions anticipated from the increased demands of crop residues, especially for biofuel production $[9,12,13]$. Despite this, up to date information regarding the spatial distribution of residue cover is still lacking. Thus, it is important to design robust approaches for monitoring the spatial distribution of residue cover especially over large areas.

Sustainable land management practices require quantitative information on the spatial variability of residue cover that remains in the field. Approximately 64.2 million dry tons of corn stover are harvested, and baled an- nually in USA [12]. The amounts of residue remaining in the agricultural field depends on the soil tillage practice, equipment, soil moisture, and wind erosion constraints [12]. According to [14], soil tillage practices vary spatially, and temporally depending on the economic, and environmental conditions. While conventional tillage practices aerate the soil, and increase microbial activity responsible for oxidizing crop residue, conservation tillage practices limit microbial oxygen supply, and reduce microbial activity, lowering soil carbon consumption [11]. Conservation tillage as defined by the conservation technology information center [15] is any tillage system that maintains at least $30 \%$ of the soil surface covered by residue primarily to minimize soil erosion. Other benefits of conservation tillage include a reduction in the number of tillage operations, amount of fuel used, irrigation costs, amount of dust generated, and the volume of soil disturbed [16-19]. This article not only provides new insight into remote sensing based approaches for estimating surface residue cover but also outlines the methods that were previously or currently being used for residue assessment including their merits, and demerits, as well as discusses in detail the costs, and benefits of residue management.

\section{Crop Residue Assessment Methods}

Visual estimations, line transect, and other ground based (fieldwork) procedures have long been, and currently are the mainstream in residue assessment $[20,21]$. Although 
field measurements can generate accurate estimates of residue cover especially within the immediate sample location, they are time consuming, unsuitable for large areas, and require complex sampling, and extrapolation. The availability of an increasing number of satellites renders the potential to deliver frequent residue estimation maps for large spatial extents. However, the development of efficient methods for monitoring crop residues is a challenging task. For example, remote sensing data analysis utilizes predominantly per pixel classification [22]. This approach fails to accurately capture the inherent variation created by mixtures of different materials within the pixel [23] such as differences in shape, size, color, texture, and level of compactness. Models for estimating crop residue cover fraction have recently been developed, and tested $[6,14,18,24-28]$ with mixed success. From a practical standpoint, indices such as cellulose absorption index (CAI), and the lignin cellulose absorption index (LCA) which are based on cellulose associated broad absorption features $(2100 \mathrm{~nm}$ and $2300 \mathrm{~nm}$ wavelength) appearing in the reflectance spectra of crop residues, but absent in the reflectance spectra of soils, are unsuitable for mapping residue cover, largely because most satellite sensors are not sensitive within the specified spectral range $[18,20,26,29]$.

Other workers [13] investigated the spatial variation of residue cover in recently planted agricultural fields. The inaccuracy of the map products generated from such approaches may be explained by the anticipated confusion between the spectral signatures of the soils, residues, and the standing crops. For example, it is virtually impossible to retrieve pure endmembers from spectral measurements acquired in a field with a mixture of standing crops, and residues. Errors do occur in situations where the spectral differences between classes, such as soils, and residue cover are not sufficiently large for discrimination [20]. Other difficulties in mapping residues stem from the varied spectral signature caused by the decomposition of residues over time [14]. The decomposition of crop residues (e.g. by soil organisms) is largely influenced by temperature, and moisture [3]. Other factors to consider in residue mapping include keeping up to date with the rapidly evolving technologies such as remote sensing, and data processing systems.

Other anticipated problems in remote sensing include atmospheric effects such as cloud cover, scan gaps for example in Landsat ETM+ satellite imagery, bidirectional reflectance distribution function (BRDF), and data misregistration. Cloud cover can be masked out, however this creates data gaps. To minimize the radiometric and atmospheric effects, normalization of satellite imagery is conducted. However, normalization requires an assumption of a lambertian surface, a large homogeneous target, and also that the target (e.g. vegetation) used for nor- malization is stable. Normalization can especially be useful when conducting analyses over multiple scenes but for single scenes, raw digital numbers from the satellite imagery could suffice. Other pertinent issues to consider include the availability of satellite imagery for the dates when the field work was conducted, given the short time window between harvest and residue removal. [18,26] reported that differing surface moisture content, and soil types can result to different spectral reflectance.

\section{Costs and Benefits of Conservation Tillage}

Conservation tillage is more profitable than conventional tillage due to reduced labor, equipment, and can provide baseline information for monitoring compliance in a carbon trading system [18]. Furthermore, conservation tillage systems leave substantial amounts of crop residues on the soil surface that can improve soil structural attributes, act as barrier to wind and water erosion, and as mulch for nutrient cycling potentially minimizing the need for fertilizers [12,26,30]. More recently, [31] estimated erosion soil losses due to conventional tillage practices in the United States as $8619 \mathrm{~kg} / \mathrm{ha} /$ year, while losses associated with conservational tillage practices were only $328 \mathrm{~kg} / \mathrm{ha} /$ year. [32] reported that conservation tillage can sequester carbon at a rate of up to 300 $\mathrm{kg} / \mathrm{ha} /$ year, unlike conventional tillage methods which exhibit no net carbon sequestration. [7] reaffirms the importance of corn residues as reservoirs for elements such as carbon, calcium, potassium, nitrogen and phosphorus. A preliminary study by [7] found that removal of corn residues decreased soil organic carbon concentration, increased the soil's susceptibility to compaction and reduced crop yields, though the effects were soil specific. [5] adds that residue management is important for controlling nitrogen dynamics and preventing nitrate leaching.

Plant residues influence soil temperature regimes and radiation balance by intercepting solar radiation and insulating the soil, thereby reducing thermal variations, minimizing evaporation from the soil, and consequently increasing water availability in the root zone $[1,33,34]$. [1] reported that corn emergence is sensitive to variations in soil water and temperature regimes. Changes in soil temperature produced by plant residue may directly influence plant growth, rate of mineralization, and consequently nutrient availability [35]. Therefore, excessive harvesting of surface corn residues for biofuel or feed production may adversely affect future crop yields and environmental quality by altering soil properties. However, [1] cautioned that mulched soils may also have negative consequences for example, delayed corn emergence due to slow soil warming in mulched soils may cause reduction in grain yields by $35 \%-50 \%$ in comparison to unmulched soils. 


\section{Crop Residue Cover Modeling}

Models serve two main objectives: 1) description, in that a model represents the systematic structure of the data as simply as possible and 2) prediction, because a model can be used to predict unobserved data [36]. Linear regression is mostly used in modeling because it meets both of the stated criteria. Quantification of the added value of retaining crop residues in the soil and the consequences of management changes on carbon sequestration requires models that can enable the prediction of the environmental impact of residue management under various scenarios [5]. However, modeling crop residues is a difficult problem. The substantial body of work on residue estimation has not produced a feasible and practical approach for mapping residue cover over large areas. Furthermore, the extraction of distinct residue spectral signatures from satellite imagery has not yet been fully solved. Currently, the spatial variation in residue cover is characterized with the aid of approaches such as linetransect, visual estimation, photographic techniques and so forth. However acquiring accurate estimates of residue cover visually can be challenging because human observers often have difficulty distinguishing small differrences in residue cover, for example near the $30 \%$ residue cover threshold which is useful for discriminating conventional versus conservation tillage [14].

A large number of residue models have been proposed and developed $[18,24,26,28,29,37]$, none of which provide validated map products of tillage practices. [20] points out that the main difference between satellite and ground based data is the ability of satellite data to capture data on spatially continuous grids or pixels, unlike ground based data which are mostly composed of discrete sampled points requiring interpolation. Ground based data are however useful for calibration, and validating satellite products.

[6] proposed hyperspectral probe-1 for estimating residues in agricultural lands using a constrained linear mixture analysis approach. However, the endmembers for residues, bare soil and vegetation were manually extracted from the satellite imagery which can contain errors such as those arising from the diffuse radiations from the atmosphere. [38] stated that poor endmember selection can lead to meaningless percent fraction cover maps, more so if the endmember fractions are inaccurate in a physical sense. Although airborne hyperspectral imagery provide high resolution data with good signal-to-noise ratio (SNR), their spatial coverage is limited, acquisitions costly, and scheduling depends on the availability of the instruments. Spaceborne hyperspectral sensors such as EO-1 Hyperion which were useful for the CAI and LCA, is past its operational lifetime and suffers bad detector lines [39]. Other indices such as the Normalized Difference Index
[40] and the crop residue index multiband (CRIM) developed from spectral band differrences and ratios of Landsat thematic mapper [26,41], produce poor results due to similarity in properties between crop residues and soil. [20] suggested two approaches for discriminating crop residues from soil, one was based on fluorescence emissions and the other on shortwave infrared reflectance. The fluorescence approach was based on the idea by [37] that crop residues fluoresce more than soils under ultraviolet radiation. However, the relatively weak fluorescence signal compared to normal sunlight which makes it necessary to either shield the system from sunlight or operate at night and the need for adequate excitation energy, are among the major drawbacks facing the utilization of the florescence approach for residue mapping [20].

Remote sensing techniques can provide a uniform approach for modeling the spatial variation in residue cover on a continuous surface over large areas, unlike ground based methods which rely on sampling and interpolation. However, several obstacles stand in the way of modeling spatial variation in residue cover using remote sensing. One of the principal methods of assessing variability of land cover over large areas using remote sensing is through the supervised classification [42]. However, it is difficult to select training classes of residues to conduct a supervised classification, because of the scattered nature of residue cover. Furthermore, it is pointless to develop residue models with only a single spectral band, because the spectral reflectance curves for residue cover is variable both spatially and temporally. Therefore, alternative approaches such as designing models with more spectral information need to be further investigated. Many prior studies have acknowledged the difficulty in modeling residue cover, but failed to provide robust and practicable models that can be utilized especially with data from existing broadband satellite remote sensing systems. This article suggests the use of ground based measurements (e.g. see [21]) to model and extrapolate residue cover variations to regional scale using satellite imagery and spectral mixture analysis technique.

\section{Why Spectral Mixture Analysis (SMA)?}

Spectral Mixture Analysis is useful for mapping crop residues because it decomposes the $\mathrm{DN}$ or reflectance values into fraction images thereby minimizing the mixed pixel problem inherent in such mapping activities [6]. Mixed pixels contain fractions of two or more pure target surface classes within an image, usually referred to as end-members. [43] states that the relative contribution of a given endmember to a mixed spectrum of a pixel is equivalent to the surface abundance of the respective land cover class in that pixel. Spectral un-mixing applies 
matrix inversion to retrieve the abundances or fractions of a number of pure spectral components that best explain the observed mixed pixel. Furthermore, spectral mixture analysis utilizes information from all available bands to establish the contribution of non photosynthetic vegetation (NPV), green vegetation (GV), soil and shade to the total reflectance [17]. Spectral mixture analysis is therefore a deconvolution technique applied on the pixel, assuming that each pixel on the surface is a physical mixture of several constituents weighted by surface abundance $[23,44]$.

The reflectance of a pixel $\left(R_{b}\right)$ in SMA is determined by a linear combination of $n$ pure spectra $[45,46]$, such that:

$$
R_{b}=\sum_{i=1}^{n} F_{i} R_{i, b}+\varepsilon_{b}, \text { for } \sum_{i=1}^{n} F_{i}=1
$$

where $R_{b}$ can be the $\mathrm{DN}$, radiance or reflectance value in band $b, F_{i}$ the fractional abundance of endmember $i, n$ is the total number of endmembers, $R_{i, b}$ is the reflectance for endmember $i$ in band $b$, and $\varepsilon_{b}$ is the residual error (observed-predicted) in band b of the model. The SMA fraction products (GV, NPV, soil and shade) should have per pixel values that range between 0 and 1. The SMA model error is estimated for each image pixel by computing the RMS error, given by:

$$
\mathrm{RMS}=\left[\mathrm{n}^{-1} \sum_{b=1}^{n} \varepsilon_{b}\right]
$$

SMA is assumed to have a linear relationship though in reality SMA does not fully account for non-linear mixing $[47,48]$. Non-linear mixing results from multiple scattering by vegetation canopies or vegetation and soil surfaces and can at times be significant $[46,49,50]$. SMA can be used to produce residue cover fractions (NPV) across a satellite imagery.

\section{Limitations of Integrated Remotely Sensed and Field Models for Estimating Surface Crop Residue Cover}

Any model, no matter how complex or simple is based on a set of assumptions, and with these assumptions arise the limitations of the model. The realization of these limitations is very important as they constitute a framework for future improvements in the model. In this article, I have suggested the use of satellite data and linear modeling techniques. Important decisions and assumptions have to be made at each stage in the analysis with regard to the limitation of the approaches and parameters. In the following points, I attempt to summarize the limitations of residue mapping and show how each point is a potential future research topic.

First, limitations can arise from the data utilized, as- sumptions and sampling protocol. For example, when modeling residue cover over large spatial extents, the need to develop non complex models results to residue moisture contents and soil moisture being largely ignored. Furthermore, to develop a comprehensive management strategy would require all crop residues within a study area to be mapped. Other major problems in residue monitoring would be related to the lack of anniversary date satellite imagery and spectral ambiguities largely attributed to atmospheric effects. With regard to sampling especially during field data collection, a strategy such as stratified sampling can be employed to target appropriate sample sizes that can capture the spatial variability of residue cover.

Secondly, fractional abundances of the NPV, GV, bare soil and shade fraction products are based on SMA assumed to be a linear combination of endmember reflectance spectra, while in reality the relation between reflectance and components in an image are non linear [23, 47,51]. Endmembers can be influenced by scattering of surface materials or other factors such as illumination geometry, which can contribute noise to the linear mixture models [52]. [6] reports that the performance of SMA is dependent on the crop residue type and recommends the acquisition of satellite imagery at post-harvest or prior to spring seeding so as to simplify the detection of percent residue cover by avoiding the confusion with crop canopy. [53] emphasized that the fundamental requirement for SMA is the proper determination of endmembers. However, the selection of endmembers is a subjective process. Selecting pure endmembers is critical for quantitative comparison of spatial variation of residues within a region, especially over time [17]. [6] suggested the use of multiple endmembers for better accuracy in mapping residues, while [17] advise to the contrary. For residue cover monitoring, I would recommend that from field spectral measurements or laboratory data, a robust approach be designed on how to select pure reference endmembers, so as to develop uniform mixture model. Other researchers [23] report that spectral unmixing performs well mainly with hyperspectral or high spectral resolution satellite data and could be erroneous with lower spectral resolution data such as Landsat or even AWiFS. Spectral unmixing assumes that endmembers and the spectra that together form the mixture are orthogonal and thus non-intercorrelated which is untrue [23]. [23] found that correlation of endmembers and actual spectra of material that constitute the mixture can result to erroneous SMA fraction products.

\section{Conclusions}

The purpose of this paper was to review, and provide new insights on the application of remote sensing tech- 
niques to characterize surface residue cover. Satellite remotely sensed data can be useful for extrapolating field data so as to map over broad geographical scales. Apart from having a synoptic view, satellite remote sensing has the potential to map in a repeatable format and is available in digital format.

However, using satellites to map crop residues is still at its infancy possibly due to the inherent difficulties in separating the crop residue spectral signatures from soil, the high costs in terms of technical know how and the need to frequently update remote sensing systems. The concerns raised in this article show the long path that still remains towards achieving sufficient progress in residue mapping, in which measuring and estimating spatial variability in residue is determined by several factors, such as residue type, residue moisture, soil moisture, soil types, time of year, soil organisms, and $\mathrm{pH}$ which influence residue decomposition rate, age of residue and so forth. Focus should be to develop operational systems for large scale monitoring of residue cover.

\section{REFERENCES}

[1] H. Blanco-Canqui, R. Lal, W. M. Post and L. B. Owens, "Changes in Long-Term No-Till Corn Growth and Yield under Different Rates of Stover Mulch," Agronomy Journal., Vol. 98, No. 4, 2006, pp. 1128-1136.

doi:10.2134/agronj2006.0005

[2] P. Gallagher, M. Dikeman, J. Fritz, E. Wailes, W. Gauther and H. Shapouri, "Biomass from Crop Residues: Cost and Supply Estimates," U.S.D.A., Office of the Chief Economist, Office of Energy Policy and New Uses. Agricultural Economic Report No. 819, 2003.

http://www.usda.gov/oce/reports/energy/AER819.pdf.

[3] E. Davidson, and I. Janssens, "Temperature Sensitivity of soil Carbon Decomposition and Feedbacks to Climate Change," Nature, Vol. 440, No. 9, 2006, pp. 165-173. doi:10.1038/nature04514

[4] J. Fargione, J. Hill, D. Tilman, S. Polasky and P. Hawthorne, "Land Clearing and the Biofuel Carbon Debt," Science, Vol. 319, No. 5867, 2008, pp. 1235-1238. doi:10.1126/science. 1152747

[5] P. Garnier, C. Neel, C. Aita, S. Recous, F. Lafolie and B. Mary, "Modeling Carbon and Nitrogen Dynamics in a Bare Soil with and without Straw Incorporation," European Journal of Soil Science, Vol. 54, No. 3, 2003, pp. 555-568. doi:10.1046/j.1365-2389.2003.00499.x

[6] A. Bannari, A. Pacheco, K. Staenz, H. McNairn and K. Omari, "Estimating and Mapping Crop Residue Cover on Agricultural Lands Using Hyperspectral and IKONOS Data," Remote Sensing of Environment, Vol. 104, No. 4, 2006, pp. 447-459. doi:10.1016/j.rse.2006.05.018

[7] H. Blanco-Canqui and R. Lal, "Corn Stover Removal for Expanded Uses Reduces Soil Fertility and Structural Stability," Soil Science Society of America Journal, Vol. 73, No. 2, 2009, pp. 418-426. doi:10.2136/sssaj2008.0141

[8] J. Scharlemann and W. Laurance, "How Green Are Bio- fuels?" Science, Vol. 319, No. 5859, 2008, pp. 43-44. doi:10.1126/science. 1153103

[9] T. Searchinger, R. Heimlich, R. Houghton, F. Dong, A. Elobeid, J. Fabiosa, S. Tokgoz, D. Hayes and T. Yu, "Use of U.S. Croplands for Biofuels Increases Greenhouse Gases through Emissions from Land-Use Change," Science, Vol. 319, No. 5867, 2008, pp. 1238-1240. doi:10.1126/science. 1151861

[10] D. Lu, "The Potential and Challenge of Remote SensingBased Biomass Estimation," International Journal of Remote Sensing, Vol. 27, No. 7, 2006, pp. 1297-1328. doi:10.1080/01431160500486732

[11] A. Viña, A Peters and L. Ji, "Use of Multispectral Ikonos Imagery for Discriminating between Conventional and Conservation Agricultural Tillage Practices," Photogrammetric Engineering and Remote Sensing, Vol. 69, No. 5, 2003, pp. 537-544.

[12] R. L. Graham, R. Nelson, J. Sheehan, R. Perlack and L. Wright, "Current and Potential U.S. Corn Stover Supplies," Agronomy Journal, Vol. 99, No. 1, 2007, pp. 1-11. doi:10.2134/agronj2005.0222

[13] H. Blanco-Canqui and R. Lal, "Soil and Crop Response Harvesting Corn Residues for Biofuel Production," Geoderma, Vol. 141, No. 3-4, 2007, pp. 355-362. doi:10.1016/j.geoderma.2007.06.012

[14] C. T. Daughtry, P. C. Doraiswamy, E. R. Hunt Jr., A. J. Stern, J. E. McMurtrey and J. H. Prueger, "Remote Sensing of Crop Residue Cover and Soil Tillage Intensity," Soil and Tillage Research, Vol. 91, No. 1-2, 2006, pp. 101-108. doi:10.1016/j.still.2005.11.013

[15] CTIC, "National Survey of Conservation Tillage Practices," Conservation Technology Information Center, CTIC, West Lafayette, IN., 2004.

http://ctic.purdue.edu/ctic.html

[16] N. Madden, J. Southard and P. Mitchell "Conservation Tillage Reduces PM10 Emissions in Dairy Forage Rotations," Atmospheric Environment, Vol. 42, No. 16, 2008, pp. 3795-3808. doi:10.1016/j.atmosenv.2007.12.058

[17] A. Pacheco and H. McNairn, "Evaluating Multispectral Remote Sensing and Spectral Unmixing Analysis for Crop Residue Mapping," Remote Sensing of Environment, Vol. 114, No. 10, 2010, pp. 2219-2228. doi:10.1016/j.rse.2010.04.024

[18] G. Serbin, T. Craig, C. S. T. Daughtry, E. R. Hunt Jr., D. I. Brown, and G. W. McCarty, "Effect of Soil Spectral Properties on Remote Sensing of Crop Residue Cover," Soil Science of America Journal, Vol. 73, No. 5, 2009, pp. 1545-1558. doi:10.2136/sssaj2008.0311

[19] S. Upadhyaya, K. Lancas, G. Santos-Filho and N. Raghuwanshi, "One-Pass Tillage Equipment Outstrips Conventional Tillage Method," California Agriculture, Vol. 55, No. 5, 2001, pp. 44-47. doi:10.3733/ca.v055n05p44

[20] E. M. Barnes, K. A. Sudduth, J. W. Hummel, S. M. Lesch, D. L. Corwin, C. Yang, C.T. Daughtry and W. C. Bausch, "Remote- and Ground-Based Sensor Techniques to Map Soil Properties," Photogrammetric Engineering \& Remote Sensing, Vol. 69, No. 6, 2003, pp. 619-630.

[21] N. Wollenhaupt, "Estimating Residue: Line Transect Me- 
thod," G1570, MU extension, 1993.

http://extension.missouri.edu/publications/DisplayPub.asp $\mathrm{x} ? \mathrm{P}=\mathrm{G} 1570$ (accessed online on $14^{\text {th }}$ January 2011).

[22] J. Ju, E. Kolaczyk and S. Gopal, "Gaussian Mixture Discriminant Analysis and Sub-Pixel Land Cover Characterization in Remote Sensing," Remote Sensing of Environment, Vol. 84, No. 4, 2003, pp. 550-560. doi:10.1016/S0034-4257(02)00172-4

[23] F. van der Meer and S. de Jong, "Improving the Results of Spectral Unmixing of Landsat Thematic Mapper Imagery by Enhancing the Orthogonality of End-Members," International Journal of Remote Sensing, Vol. 21, No. 15, 2000, pp. 2781-2797. doi:10.1080/01431160050121249

[24] C. T. Daughtry, E. R. Hunt Jr., P. C. Doraiswamy, J. E. McMurtrey, "Remote Sensing the Spatial Distribution of Crop Residues," Agronomy Journal, Vol. 97, No. 3, 2005, pp. 864-871. doi:10.2134/agronj2003.0291

[25] C. T. Daughtry and E. R. Hunt Jr., "Mitigating the Effects of Soil and Residue Water Contents on Remotely Sensed Estimates of Crop Residue Cover," Remote Sensing of Environment, Vol. 112, No. 4, 2008, pp. 1647-1657. doi:10.1016/j.rse.2007.08.006

[26] B. K. Gelder, A. L. Kaleita and R. M. Cruse, "Estimating Mean Field Residue Cover on Midwestern Soils Using Satellite Imagery," Agronomy Journal, Vol. 101, No. 3, 2009, pp. 635-643. doi:10.2134/agronj2007.0249

[27] G. Serbin, C. S. T. Daughtry, R. Hunt Jr., J. Reeves and D. I. Brown, "Effect of Soil Composition and Mineralogy on Remote Sensing of Crop Residue Cover," Remote Sensing of Environment, Vol. 113, No. 1, 2009, pp. 224-238. doi:10.1016/j.rse.2008.09.004

[28] D. Thoma, C. Gupta and E. Bauer, "Evaluation of Optical Remote Sensing Models for Crop Residue Cover Assessment," Journal of Soil and Water Conservation, Vol. 59, No. 5, 2004, pp. 224-233.

[29] G. Serbin, E. R. Hunt Jr., C. S. T. Daughtry, G. W. McCarty and P. C. Doraiswamy, "An Improved ASTER Index for Remote Sensing of Crop Residue," Remote Sensing, Vol. 1, No. 4, 2009, pp. 971-991. doi:10.3390/rs1040971

[30] N. D. Uri, J. D. Atwood and J. Sanabria, "The Environmental Benefits and Costs of Conservation Tillage," Environmental Geology, Vol. 38, No. 2, 1999, pp. 111-125.

[31] S. South, J. Qi and D. Lusch, "Optimal Classification Methods for Mapping Agricultural Tillage Practices," Remote Sensing of Environment, Vol. 91, No. 1, 2004, pp. 90-97. doi:10.1016/j.rse.2004.03.001

[32] G. Robertson, P. Eldor and R. Harwood, "Greenhouse Gases in Intensive Agriculture: Contributions of Individual Gases to the Radiative Forcing of the Atmosphere," Science, Vol. 289, No. 5486, 2000, pp. 922-925. doi:10.1126/science.289.5486.1922

[33] R. A. Evans and J. Young, "Plant Litter and Establishment of Alien Annual Weed Species in Rangeland Communities," Weed Science, Vol. 18, 1970, pp. 697-703.

[34] E. A. Holland and D. C. Coleman, "Litter Placement Effects on Microbial and Organic Matter Dynamics in an Agroecosystem," Ecology, Vol. 68, No. 2, 1987, pp. 425-
433. doi: $10.2307 / 1939274$

[35] A. K. Knapp and T. R. Seastedt, "Detritus Accumulation Limits Productivity of Tallgrass Prairie," Bioscience, Vol. 36, No. 10, 1986, pp. 622-688. doi:10.2307/1310387

[36] G. De'ath and K. Fabricius, "Classification and Regression Trees: A Powerful yet Simple Technique for Ecological Data Analysis," Ecology, Vol. 81, No. 11, 2000, pp. 31783192.

doi:10.1890/0012-9658(2000)081[3178:CARTAP]2.0.C $\underline{\mathrm{O} ; 2}$

[37] J. E. McMurtrey III, E. W. Chappelle, C. T. Daughtry and M. S. Kim, "Fluorescence and Reflectance of Crop Residue and Soil," Journal of Soil and Water Conservation, Vol. 48, No. 3, 1993, pp. 207-213.

[38] S. Tompkins, J. F. Mustard, C. M. Pieters and D. W. Forysth, "Optimization of Endmembers for Spectral Mixture Analysis," Remote Sensing of Environment, Vol. 59, No. 3, 1997, pp. 472-489. doi:10.1016/S0034-4257(96)00122-8

[39] USGS, "Earth Observing 1 (EO-1): Sensors-Hyperion," EROS Data Center, USGS, Sioux Falls, SD, 2007. eo1.usgs.gov/hyperion.php

[40] H. McNarin and R. Protz, "Mapping Corn Residue Cover on Agricultural Fields in Oxford County, Ontario, Using Thematic Mapper," Canadian Journal of Remote Sensing, Vol. 19, No. 2, 1993, pp. 152-159.

[41] F. Biard and F. Baret, "Crop Residue Estimation Using Multiband Reflectance," Remote Sensing of Environment, Vol. 59, No. 3, 1997, pp. 530-536. doi:10.1016/S0034-4257(96)00125-3

[42] G. Foody and A. Mathur, "The Use of Small Training Sets Containing Mixed Pixels for Accurate Hard Image Classification: Training on Mixed Spectral Responses for Classification by SVM," Remote Sensing of Environment, Vol. 103, No. 2, 2006, pp. 179-189.

doi:10.1016/i.rse.2006.04.001

[43] M. O. Smith, S. L. Ustin, J. B. Adams and A. R. Gillespie, "Vegetation in Deserts: I.A Regional Measure of Abundance from Multispectral Images," Remote Sensing of Environment, Vol. 31, No. 1, 1990, pp. 1-26. doi:10.1016/0034-4257(90)90074-V

[44] M. O. Smith, P. E. Johnston and J. Adams, "Quantitative Determination of Mineral Types and Abundances from Reflectance Spectra Using Principal Component Analysis," Journal of Geophysical Research, Vol. 90, 1985, pp. 797-804.

[45] P. E. Dennison and D. A. Roberts, "Endmember Selection for Multiple Endmember Spectral Mixture Analysis Using Endmember Average RMSE," Remote Sensing of Environment, Vol. 87, No. 2-3, 2003, pp. 123-135. doi:10.1016/S0034-4257(03)00135-4

[46] D. A. Roberts, M. O. Smith and J. B. Adams, "Green Vegetation, Non-Photosynthetic Vegetation, and Soils in AVIRIS Data," Remote Sensing of Environment, Vol. 44, No. 2-3, 1993, pp. 255-269. doi:10.1016/0034-4257(93)90020-X

[47] D. Roberts, M. Gardner, R. Church, S. Ustin, G. Scheer and R. Green, "Mapping Chaparral in the Santa Monica 
Mountains Using Multiple Endmember Spectral Mixture Models," Remote Sensing of Environment, Vol. 65, No. 3,1998, pp. 267-279. doi:10.1016/S0034-4257(98)00037-6

[48] Fan Wenyi, H. Baoxin, M. John and L. Mingze, "Comparative Study between a New Nonlinear Model and Common Linear Model for Analyzing Laboratory Simulated-Forest Hyperspectral Data," International Journal of Remote Sensing, Vol. 30, No. 11, 2009, pp. 2951-2962. doi: $10.1080 / 01431160802558659$

[49] A. R. Huete, "Separation of Soil-Plant Spectral Mixtures by Factor Analysis," Remote Sensing of Environment, Vol. 19, No. 3, 1986, pp. 237-251. doi:10.1016/0034-4257(86)90055-6

[50] T. W. Ray and B. C. Murray, "Nonlinear Spectral Mixing in Desert Vegetation," Remote Sensing of Environment, Vol. 55, No. 1, 1996, pp. 59-64. doi:10.1016/0034-4257(95)00171-9

[51] I. Numata, D. Roberts, O. Chadwick, J. Schimel, F. Sampaio, F. Leonidas and J. Soares, "Characterization of Pasture Biophysical Properties and the Impact of Grazing Intensity Using Remotely Sensed Data," Remote Sensing of Environment, Vol. 109, No. 3, 2007, pp. 314-327. doi:10.1016/j.rse.2007.01.013

[52] F. J. Garcia-Haro, M. A. Gilabert and J. Meliả, "Extraction of Endmembers from Spectral Mixtures," Remote Sensing of Environment, Vol. 68, No. 3,1999, pp. $237-$ 253. doi:10.1016/S0034-4257(98)00115-1

[53] D. R. Peddle and A. M. Smith, "Spectral Mixture Analysis of Agricultural Crops: Endmember Validation and Biophysical Estimation in Potato Plots," International Journal of Remote Sensing, Vol. 26, No. 22, 2005, pp. 4959-4979. doi:10.1080/01431160500213979 